\title{
On-street Parking Management in Megacity: Case Study of Central Area of Ho Chi Minh City
}

\author{
Vo Minh Phuc ${ }^{1}$, Tran Van Tao ${ }^{2}$, Vo Trong Cang ${ }^{2, *}$ \\ ${ }^{1}$ Sustainable Urban Development, Vietnamese-German University, Ho Chi Minh City, Vietnam \\ ${ }^{2}$ Faculty of Transportation Engineering, Ho Chi Minh City University of Technology, Ho Chi Minh City, Vietnam \\ Email address: \\ vominh.phuc95@gmail.com (Vo M. Phuc), tao.tranvan@hcmut.edu.vn (T. V. Tao), vtcang@hcmut.edu.vn (Vo T. Cang) \\ ${ }^{*}$ Corresponding author
}

\section{To cite this article:}

Vo Minh Phuc, Tran Van Tao, Vo Trong Cang. On-street Parking Management in Megacity: Case Study of Central Area of Ho Chi Minh City. International Journal of Mechanical Engineering and Applications. Special Issue: Transportation Engineering Technology - Part IV.

Vol. 7, No. 6, 2019, pp. 136-142. doi: 10.11648/j.ijmea.20190706.12

Received: November 7, 2019; Accepted: November 29, 2019; Published: December 4, 2019

\begin{abstract}
One of the problems of urban transport is parking planning. The population of Ho Chi Minh City (HCMC) reached 8.6 million units in 2017 , and about $80 \%$ of the total population owned motor vehicles with 7.6 million vehicles. The high rate of mechanization causes a large load on the existing transport infrastructure, negatively affecting the quality of life of residents and preventing the City government from achieving the goals of sustainable urban development. Transport management is a complex operation, including on-road parking systems. Ben Nghe Ward of District 1, located in the central area of Ho Chi Minh City, has become one of the pilot areas to deploy a new parking plan from 2018. After a year of pilot implementation, the effectiveness has not yet achieved the expected effect. Therefore, this study is proposed to evaluate new possibilities to maximize the effectiveness of future road management. Within the scope of this research paper, the topic of the research and the issues are raised as well as clarifying the scope of the research. Moreover, the research objectives and questions are made to begin research correctly. In addition, necessary research methods and data collection methods are also identified for successful research.
\end{abstract}

Keywords: On-street Parking, Transport Planning, Infrastructure Planning, Ho Chi Minh City

\section{Introduction and Problem Statements}

\subsection{Introduction}

Ho Chi Minh City (HCMC) is referred as the megacity and the most populous city in Vietnam by media. Since 2017, there are more than 13 million living in the metropolitan area of HCMC [1].

Since the beginning of 21 st century, the number of vehicles in HCMC, Vietnam has growth rapidly, reaching a total of 7.5 million in 2016. As a result, traffic congestion has become one of the city's biggest problems (Figure 1).

In order to improve the traffic condition in the Central area, the City authority is finding many solutions as bike-sharing [2] or river bus systems [3], especially in parking management. Recently, Ho Chi Minh City Department of Transportation, Department of Architecture and Planning have proposed the on-street parking management schemes. The new parking management scheme has been pilot implemented in Central
Area of Ho Chi Minh City [4, 5].

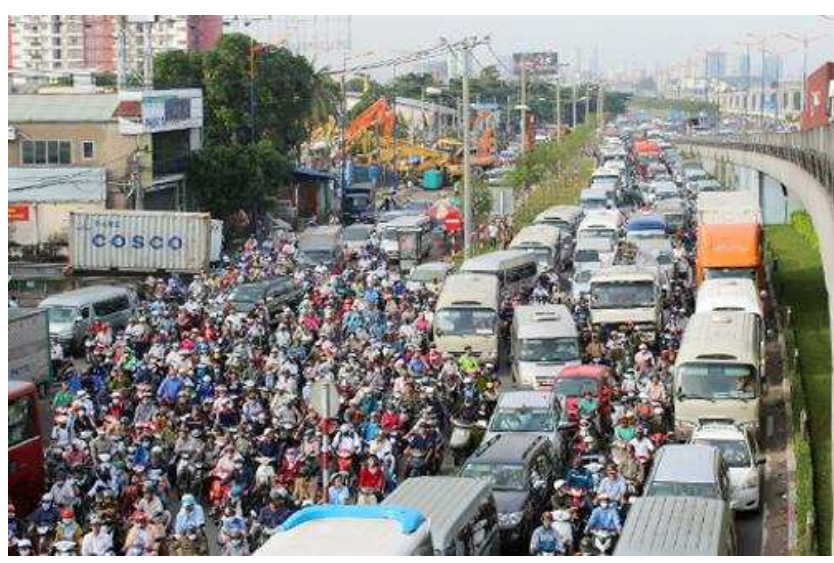

Figure 1. Traffic congestion in Ho Chi Minh city (Sources: VietNamNet).

The effort from City government has not gained its expectation. In fact, a year after the first pilot in August of 
2018, on-street car parking management scheme has been facing many problems [6].

In the other hands, the City government has keen on improving, developing their traffic management tools and efforts toward the effective transportation, through the establishments of specialized centers: Ho Chi Minh City Intelligent Traffic Control Center, Road Traffic Management Center (Figure 2).

Therefore, the assessment research on efficiency of on-street parking management is needed to conducted, in order to clarify the problems existing and propose solutions to maximize the on-street parking utilities.

This scientific paper is conducted followed the first overview of the research. The paper includes the research goal, objectives and its research questions; scope of study; finally, the research methodology and applied the data collection methods.

\subsection{Problem Statements}

The parking, as an important part of transportation system, has great impact on urban development. In contrast, the parking development is suffered from many problems: inefficient used, illegal space occupation, lack of investment management - control - enforcement, etc. In management term, the weaknesses in pricing mechanism and provision of on-street parking have cause over-used parking occupations, traffic jam, low quality traffic flow, encourage individual traffic as same as discourage public transport demand, etc. In widen scale, the adequate management strategic plan for on-street parking development would greatly contribute to the success of urban development plan toward sustainable development goal through encourage public transport use as well as balance the individual vehicles used, increase the land use effectiveness, encourage lively economic activities and harmonized the traffic flow pressure, etc. Therefore, parking management has become an attractive research topic through decades.

In 2011, Asia Development Bank (ADB) has conducted a research on parking policies system in 11 Asian cities of different countries, especially Hanoi the Capital City of Vietnam [7]. The research includes not only parking supply, parking pricing and others related policies but also their implementation and affects to different urban areas and specific context. Moreover, the research also includes the on-street parking policies, their management mechanism and enforcement which contain many related data and knowledge on management of on-street parking.

Interamerican Development Bank (IDB) has published the Practical Guidebook on Parking and Travel Demand Management (TDM) Policies in Latin America in 2013 that lists out and summaries some typical problems and challenges in parking management and TDM implementing methods [8]. After each case of example, IDB has also proposed the recommendations for each case. The challenges in parking policies are listed as follow:

1. Parking excess supply: The cities usually made mistakes in providing more parking lots than the actual demand of people which create the waste in land fund and other resources. This situation proves that there is a need for TDM policies in parking management;

2. Subsidies for parking operations: the common problem in many parking development project in particular and transportation projects in general is the establishing a "demand guarantee" for operators that the government would have to pay the operator the value of revenue that not reach the "guarantee" level;

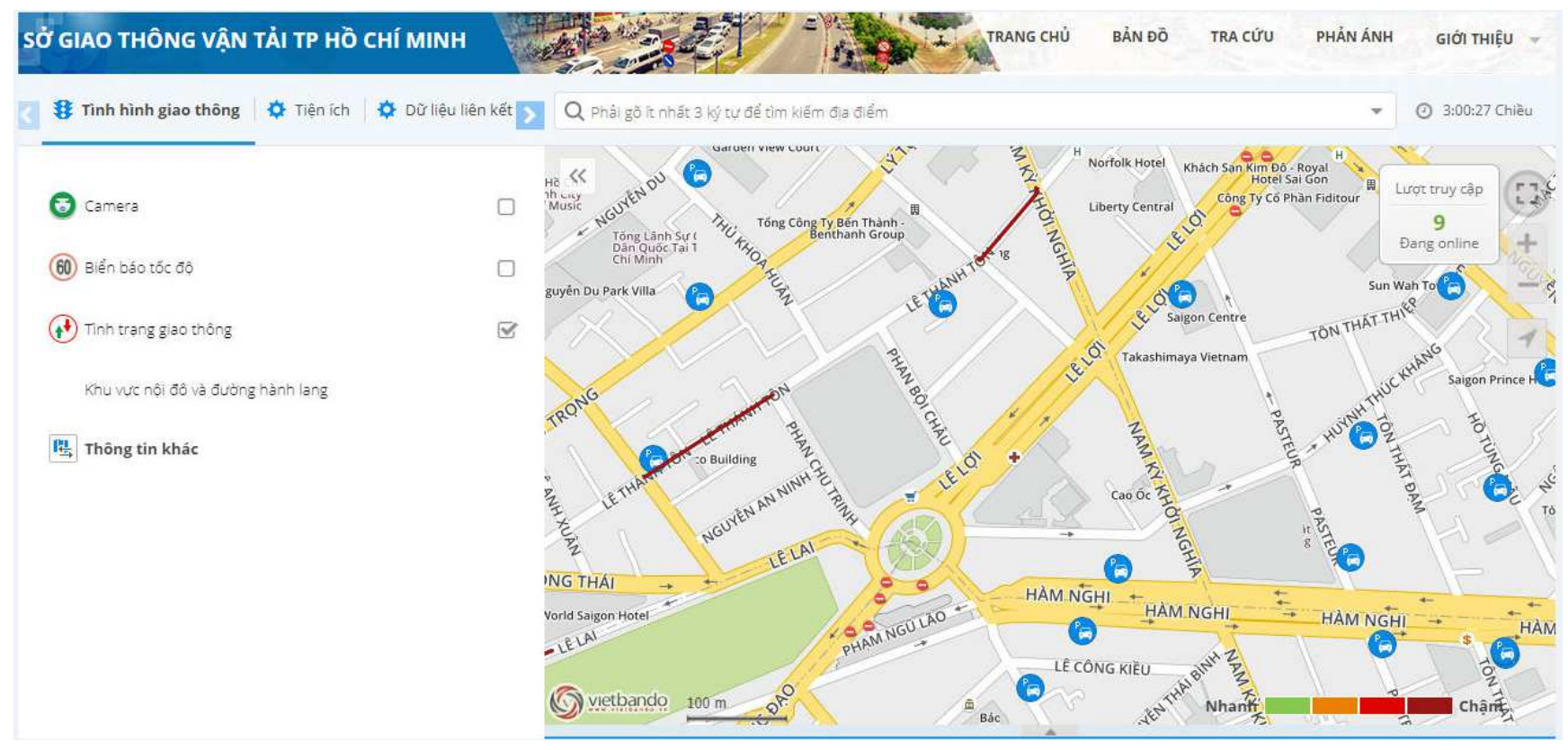

Figure 2. Intelligent traffic map of HCMC Department of transportation (Sources: http://giaothong.hochiminhcity.gov.vn/). 
3. Transition from On-street to Off-street: The parking development policies that try to eliminate the on-street parking and creating more off-street parking facilities without serious control on total parking supply and actual demand would cause saturate road way and negative effects on efficiency of public transportation systems;

4. Fixed parking price: For easier to regulated, many cities have applied the fixed parking price policies. The wrong awareness on parking price, ignoring the market rules of land, services supply and demand, causes limitation in potential interest rate that investors can rise from parking investment and difficulties in private funding to establish more parking projects. Moreover, the free charged on-street parking would also cause the inefficient use of off-street parking in the same area;

5. Ad hoc price setting for informal parking: would cause the increase in establishment of informal parking which would contribute to obstacles system of TDM policies implementation in particular and urban planning in general, such as: inefficiency information system, capacity supply-demand control, and land use, etc.;

6. Minimum parking requirement: the parking supply responsibility is transferred to construction building investors; therefore, price for building parking is distributed to customers. This mistake policy would increase the privacy ownership that leads to several problems to TDM policies (waste in resources for development of buildings, and integrated facilities, encourage privacy use of space, encounter sharing policy, etc.)

In 2017, Truong Thi My Thanh had conducted a research [9] on parking management strategies for Asian Countries, including Ha Noi the capital city of Vietnam. Due to the similarities, this research would provide lots of useful knowledge on management strategies for on-street parking in Central Area of Ho Chi Minh City. In detail, this literature had pointed out the comment challenges of developing cities in Asia on parking development. After studying on difficulties and conditions of cities, the management schemes had been proposed, based on combinations of concepts: spatial concept, time concept and fee concept. The study had proposed the zone-based parking management strategy and para-parking for future development in $\mathrm{Ha}$ Noi.The researchers on transportation system are interested in not only legal parking but also illegal parking, especially in Vietnam where has extremely high volume of private vehicles, immature driver's behaviors, inefficiency parking supply and inadequate public transport system. The illegal parking has served numerous parking demands in City area since the incapacity of legal parking facilities. In contrast, the appearance of illegal parking has caused heavy negative effects on traffic conditions, especially traffic congestions and deteriorated walking environment. Therefore, in 2017, a research on "illegal parking behavior" [10] has been conducted in Ha Noi city in order to suggest solutions for address illegal parking and improve parking system in general.
The problems in implementing parking policies in Ho Chi Minh City, Vietnam in general occur with some similarities with the general problems happened to other cities around the globe, which would be discussed in detail in my research. These problems are briefly showed as below:

1. Heterogeneity in definitions and perceptions of parking behavior from state institutions;

2. Asynchronous in parking development planning and urban transport planning;

3. Inefficiency of pricing regulations;

4. Loose parking management facility and its services;

5. Lack of control and enforcement from authorized institutions.

In order to improve the problems, Ho Chi Minh City has implemented many related policies and scheme such as: minimum parking requirement policies to increase the parking supply capacity, the pilot implement duration-based parking charging scheme to increase the efficiency of car parking business, etc. In contrast, most of new parking management policies have not met the expectation recently which cause waste of resources and adverse reactions which would worse the current situation. Therefore, as important as upgrading parking policies system, conducting research on new parking policies affects and forecasting future development is also very important to successfully develop parking system in dynamic urban areas like Ho Chi Minh City.

\section{Research Goal and Objectives}

\subsection{Research Goal}

Find out solutions to improve the efficiency of on-street parking management in central districts of a mega city.

\subsection{Research Objectives}

The goal is divided into objectives as presented below:

1. Analyzing on-street parking characteristic and the current situation of on-street parking supply and demand of parking space in the research area. From analyzed results, pointing out the role of on-street parking in parking supply capability of District 1 of Ho Chi Minh City case;

2. Capturing the gap between the supply of and the demand for on-street parking in the study area: Now and in the next 10 years;

3. Reviewing the parking management regulations which are applied Ho Chi Minh City in particular and pointing out the current issues by using literature review and interviewing authorities. In the next step, searching for potential solutions to address the identified issues;

4. Anticipating behavioral responses from the users to a number of new regulations and policies;

5. Studying on potential agendas and solutions that are already experienced in others cities. The proposed solutions need to be able to implement in Ho Chi Minh City context, forwarding the comprehensive solutions. 


\subsection{Research Questions}

Based on research goal and its objectives, the main research question and sub-questions are proposed to clarify them more exactly. The main research question is "Which factors contribute to improving on-street parking management in central area of a megacity?"

In order to clarify the main research question, the sub questions are asked and would be answered in order to identify problems and solve restrictions that reduce the efficiency of on-street parking management in central districts of a mega city (table 1).

\section{Scope of Study}

\subsection{Study Area Definition}

Study area: Ben Nghe ward of District 1 of Ho Chi Minh city (see Figure 3) [11].

According to District 1 People's Committee:

1. Area: About $2.48 \mathrm{~km}^{2}$;

2. Population: 15.630 people (2013).

\subsection{Research Subjects}

Research Subject: Parking facilities and their activities located in the research area.

Among the stages (planning, design, construction, operational management), this research is limited to the management stage, but its results might be relevant to the other stages.

The research considers the following aspects which are relevant to parking managements:

1. Stakeholders and their perspectives;

2. Parking supply and pricing regulations;

3. User behaviors or responses to new parking policies.

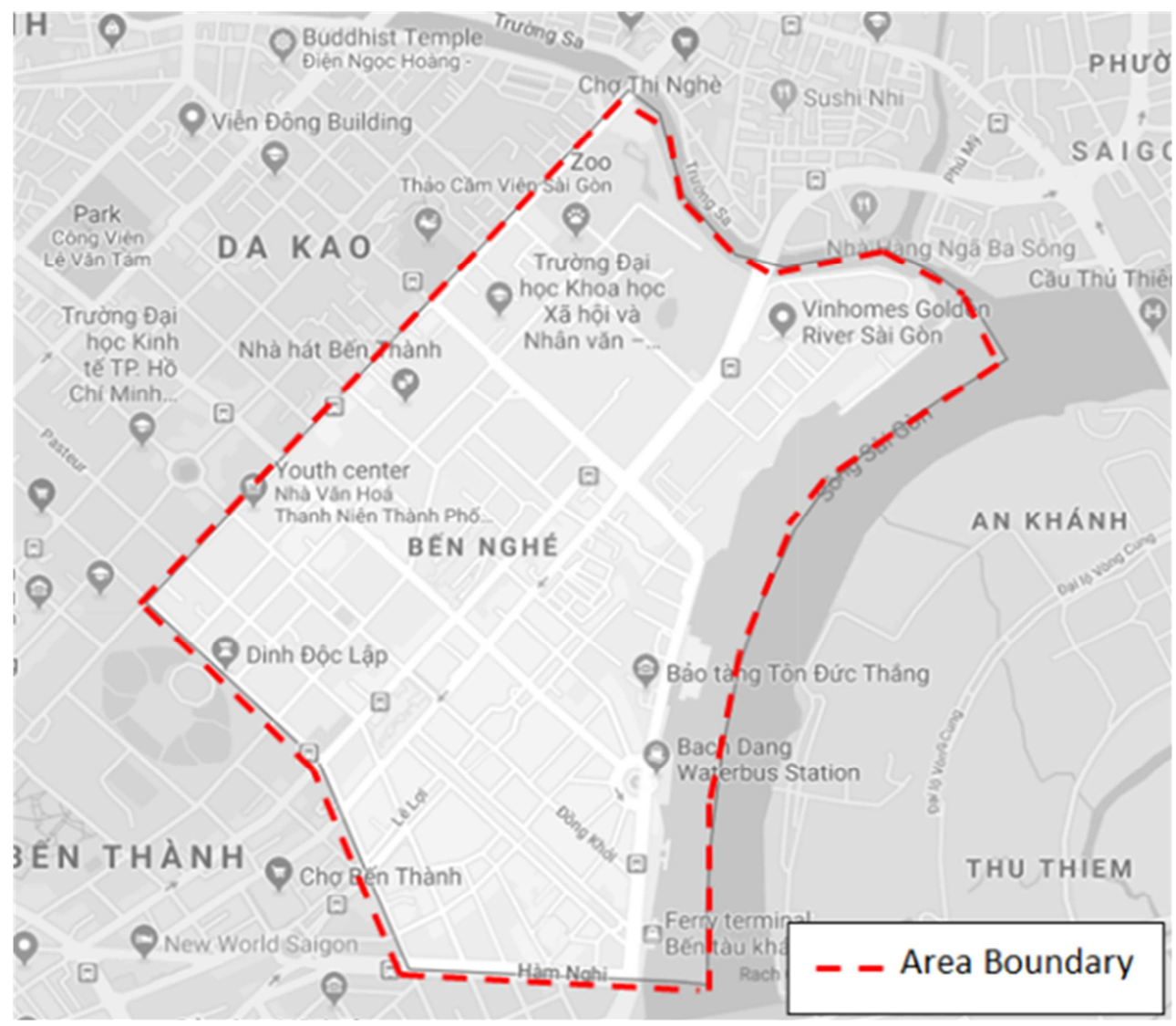

Figure 3. Definition of study area, Ben Nghe ward, District 1, HCMC

\section{Research Methodology}

\subsection{Research Type Classification and Methodology}

The research is studied as a descriptive type that aims to identify the on-street parking management facts. Moreover, this research is conducted mostly based on qualitative research methods with a little mix with quantitative research methods. In details, the featured statements and conclusions come at first from analyzed results of the human parking behaviors and stakeholders' reactions to the change of parking policies, which are hard to fully clarify by quantitative measurements. In contrary, the quantitative methods are still used as additional measures, in order to provide the supportive confirmations to those results and statements came from qualitative analysis process. Moreover, due to the research nature as a descriptive type, the research should also be conducted based on empirical research methods which could bring out the most practical data and results for research objectives, e.g. parking management status, users behaviors, stakeholders' reactions to the change in policy system, etc. 
Table 1. Sub research questions and gained information.

\begin{tabular}{|c|c|}
\hline Research questions & Working tasks \\
\hline $\begin{array}{l}\text { 1. How do different cities' government manage their parking, } \\
\text { especially on-street parking? }\end{array}$ & $\begin{array}{l}\text { 1. Review on parking management policies, mechanisms and solutions in different } \\
\text { development contexts; }\end{array}$ \\
\hline \multirow{2}{*}{$\begin{array}{l}\text { 2. What do Ho Chi Minh City's authorities do to manage and } \\
\text { develop the parking system? }\end{array}$} & $\begin{array}{l}\text { 2a. Understand the current management mechanisms and regulations systems on } \\
\text { on-street parking management in Vietnam regulation system; }\end{array}$ \\
\hline & 2b. Understand the plan for parking development in the future of Vietnam; \\
\hline $\begin{array}{l}\text { 3. How big is the gap between on-street parking supply and their } \\
\text { demand in central area of HCMC? }\end{array}$ & $\begin{array}{l}\text { 3. Based on development plan and motorization increase, assessment on parking } \\
\text { supply-and-demand gap in current state and future content; }\end{array}$ \\
\hline $\begin{array}{l}\text { 4. How do HCMC's parking users react to new parking } \\
\text { management policies (charging fee and supply)? }\end{array}$ & $\begin{array}{l}\text { 4. Assess the efficiency of new policies implementation through evaluating users } \\
\text { behaviors to new parking policies system; }\end{array}$ \\
\hline 5. What are the challenges of new policies implementing process? & 5. Identify the challenges in current and future contexts; \\
\hline $\begin{array}{l}\text { 6. What could authorities do to solve the problems and improve } \\
\text { the effectiveness of parking management? }\end{array}$ & $\begin{array}{l}\text { 6. Propose the supportive agendas and solutions for future implantation plan more } \\
\text { effective. }\end{array}$ \\
\hline
\end{tabular}

The database of the study is made up of a combination of different empirical data collection and research methods: Literature Review, Scientific observation, Sociological Investigation and In-depth Experts Interviewing.

\subsection{Data Collection Methods}

\subsubsection{Reviewing Related Documents and Case Studies (Literature Review)}

Research required relevant policy documents of Vietnam on parking management including law, policies and regulations. There are some available sources for looking up on legal documents; in this research, the main source is Law Library (link: thuvienphapluat.vn), currently the strongest website for searching Vietnamese legal documents [12,13].

The importance of parking behavior in urban infrastructure is undeniable since parking planning and operation have large affections to overall transportation planning and further affecting to sustainable development. Due to its importance role, the parking catches many scientific attentions in the effort to successfully manage the parking. There have been many studies, on parking management in general and on-street parking management in particular, conducted around the globe. Therefore, reading and summarizing previous studies $[10,14]$ are needed to understand what have been studied in the past and use obtained conclusions and results to develop my own research, in the case of Ben Nghe ward of District 1 of HCMC, Vietnam.

Since managing on-street parking or curb parking is still a new concept in Vietnam content, the experience from developed countries and urban areas which have already experienced in managing curb parking is very important to have wider range of understanding on research subject. The research on case studies also provides experience to help avoiding the same mistakes again which could save time and resources for the same development.

\subsubsection{Scientific Observation}

This research is conducted as empirical research. Therefore, the research results would be based on practical situation of current research objectives. Different type scientific observation methods are used mixed up during site survey trips in the research area, including participated and non-participated observation method.

Firstly, the non-participated method (indirect observation) is applied in order to get the view and data as overall scale (such as: facilities organization, security observation, etc.) and summarizing data about parking users and staff behavior as the same time.

The participated observation (direct observation) method is applied in order to consolidate the data collected by non-participated method. The participated observation method brings the detailed and direct point of view on on-street parking activities and others research objectives. Moreover, this practical method brings out the most direct experience on using on-street parking services.

\subsubsection{Sociological Investigation}

The sociological investigation method is applied through distribution of questionnaires and performance of site surveys interviewing toward different parking management stakeholders.

Firstly, the questionnaires are distributed to different locations inside the research area in order to collect data on user's behaviors and reactions to parking regulation changes and other management aspects such as service quality and satisfaction level on comfort, security, friendliness, pricing and accessibility, etc. The expected numbers of interviewees are 150 to 200 to ensure the confidence of $95 \%$ and confidence interval of $7-8 \%$ based on confidence level and interval concepts [15].

Secondly, the site interviewing will be applied during the site survey process, mixed with questionnaire distribution process. The depth of interview questions, using for different interviewee targets, are different based on their knowledge and experience on parking management topic and their roles between many stakeholder groups. For example, the interview questions for parking users are different to parking owners, staff and would be different from interview questions of authority's staff and public servants. The interview results are used to test the accuracy of questions which are answer in their questionnaire and add more information that were not discussed in questionnaire. 


\subsubsection{In-depth Interview Experts}

Finally, the In-depth Interviewing Experts method is applied to collect scientific knowledge related to research objectives and contribution comments on current situations of parking management and related subjects which were not clarified through other data collection methods.

The targets for in-depth interviewing are chosen carefully, considering experts' fields of research majorities, research background and their roles in Ho Chi Minh City urban development, especially in transportation planning aspects. In fact, HCMC Department of Planning and Architecture, HCMC Department of Transportation and HCMC Department of Construction are the highest three responsibility authorities in parking planning, management and development in Ho Chi Minh City area.

\subsection{Research Implementation Process}

Step 1: Mostly applying literature review to understand possible knowledge, information and data of previous studies, regulation and case studies on parking management. In detailed, reviewing regulation system applied in Ho Chi Minh City would show the authorities' opinions on on-street parking management and relative subjects;

Step 2: Identifying the current situation of on-street parking management by using combinations between observation and site survey methods;

Step 3: Studying on measures and evaluating those possibility after finalizing existing problems of research objectives are the next step.

\subsection{Structure of Final Project Report}

The main chapters of the project are listed as follow:

1. On-street parking management strategies for city central areas: Parking management strategies for cities' central area, literature review from different countries contexts;

2. Assessment of on-street parking supply-demand gap in central districts of $\mathrm{Ho}$ Chi Minh City (HCMC): Assessing the on-street parking supply-demand gap in central districts of HCMC;

3. Assessment of parking regulations and policies in HCMC: Reviewing the parking regulations and policies in $H C M C$; Assessing the efficiency of regulations and policies implementation;

4. In-depth analysis of user behaviors in central districts of $H C M C$ : Based on assessment results, in-depth analysis of user behaviors in central districts of HCMC.

\section{Conclusions}

The transportation management is the complicated operation; including the on-street parking system. The effective management requires the comprehensive assessment on several aspects: the technical availabilities, regulation system, user behaviors and development planning of City (urban planning, transportation systems, etc.).

Aiming to accurate assess, several data collection methods are applied: Literature review (Secondary data), scientific observation, sociological investigation and in-depth interview experts (Primary data). The collected data would be analyzed and evaluated to clarify the good and not-good-yet aspects of current on-street parking management in HCMC.

In scope of this research paper, the research topic and problems are stated as well as clarified the scope of study. Moreover, the research objectives and questions are conducted in order to start the study correctly. In additional, the necessary research methodology and data collections methods are also identified to conduct the research successfully.

\section{Acknowledgements}

Authors would like to acknowledge Prof. Hans Joachim Linke at the Technische Universität Darmstadt and Dr. Vu Anh Tuan, Director of the Vietnamese - German Transport Research Center at the Vietnamese - German University as thesis advisors of this research, and we are gratefully indebted to them for their very valuable comments on this research.

First author is also grateful to the funding received through the DAAD Scholarship and the support from VGU to undertake his Master thesis.

\section{References}

[1] Vu Vi, "Guess how many people are jamming into Saigon? Hint: It's as bad as Tokyo", VnExpress, posted Aug. 17, (2017).

[2] Vo Minh Phuc, "Possibility to Develop a Bike - Sharing System in Ho Chi Minh City", International Journal of Transportation Engineering and Technology, Vol. 2, No. 4, (2016), pp. 35-41.

[3] Vo Trong Cang, Nguyen Anh Tuan, Vo Minh Phuc, "Feasibility Study on River Bus Systems in Ho Chi Minh City", Int. J. of Engineering Research and Applications, Vol. 3, Issue 6, (2013), pp. 2128-2131.

[4] CHU, Xuan Nam; THI, Ha Dinh. "Actual situation and solutions for reducing the traffic jams and congestion in Vietnam." Advances in Natural and Applied Sciences, (2017), 11.12: $26-34$.

[5] Thu Dung, Ngoc An, "Ho Chi Minh City charges parking fees VND 20,000 - 30,000 / hour", Tuoitre Online, May 12, (2018).

[6] Ai Nhan, Thu Dung, "Ho Chi Minh City lost more than $98 \%$ of on-street parking fees", Tuoitre Online, Nov. 3, (2018).

[7] Asian Development Bank (ADB), "Parking Policies In Asian Cities", (2011).

[8] Interamerican Development Bank (IDB), "Practical Guidebook: Parking And Travel Demand Management Policies In Latin America", (2013).

[9] Truong Thi My Thanh, "Parking Management Strategies for Asian Developing Countries", PhD. Thesis, Vietnam-German University, (2017).

[10] Vu Anh Tuan, "Analysis of Illegal Parking Behavior in Hanoi City”, J. of Eastern Asia Society for Transport Studies, Vol. 12, (2017), pp. 42-437. 
[11] "Phuong Ben Nghe", District 1 People's Committee government website,

(2015) $<$ http://www.quan1.hochiminhcity.gov.vn>.

[12] Decision No. 568/QD-TTg of the Prime Minister "To approve the planning of the Ho Chi Minh city transport system up to 2020 , with a vision after 2020" (2013).

[13] Decision No. 519/QD-TTg of the Prime Minister "To approve the planning of Hanoi transport system up to 2030, with a vision to $2050 "$ "(2016).
[14] Vo Minh Phuc, Vo Trong Cang, "Transport Planning Challenges in Existing Urban Planning Process - Case of Vietnam Urban Planning", Landscape Architecture and Regional Planning. 4 (1): 10-14 (2019).

[15] Jerzy Neyman, "Outline of a Theory of Statistical Estimation Based on the Classical Theory of Probability", Philosophical Trans. of the Royal Society of London, Series A, Mathematical and Physical Science, Vol. 236, No. 767, (1937), pp. 333-380. 